\title{
Do Geese Facilitate or Compete with Wintering Hooded Cranes (Grus monacha) for Forage Resources?
}

\author{
Zhengrong Zhu ${ }^{1,2}$, Lizhi Zhou ${ }^{1,2, *}$, Chao Yu ${ }^{1,2}$, Lei Cheng ${ }^{1,2}$, Wenbin $\mathrm{Xu}^{3}$ and Yunwei Song ${ }^{3}$ \\ 1 School of Resources and Environmental Engineering, Anhui University, Hefei 230601, China; \\ zzrapple@foxmail.com (Z.Z.); yc-107@163.com (C.Y.); chenglei@stu.ahu.edu.cn (L.C.) \\ 2 Anhui Province Key Laboratory of Wetland Ecosystem Protection and Restoration (Anhui University), \\ Hefei 230601, China \\ 3 Anhui Shengjin Lake National Nature Reserve, Chizhou 247200, China; xuwbvip@163.com (W.X.); \\ zhuzr794@gmail.com (Y.S.) \\ * Correspondence: zhoulz@ahu.edu.cn
}

Received: 24 February 2020; Accepted: 13 March 2020; Published: 18 March 2020

\begin{abstract}
Foraging is the key behavior of waterbirds, which profoundly affects the survival of their population, and it is affected by interspecific interaction. At Shengin Lake in China, owing to the reduced availability of suitable habitats for a large population of migratory waterbirds (especially wild geese) over winter, mixed species foraging inevitably occurs. This study aimed to investigate whether mixed-species foraging affects the foraging of hooded cranes (Grus monacha). Fields surveys were carried out at Shengin Lake from November 2018 to March 2019. Mixed-species foraging was surveyed between the flocks of hooded cranes and three species of geese, greater white-fronted geese (Anser albifrons), lesser white-fronted geese (Anser erythropus) and bean geese (Anser fabalis). Instantaneous scanning and focal animal methods were used to collect behavioral samples of hooded cranes. The quadrat method was used to survey the food density in three habitats: meadows, mudflats, and paddy fields. The results showed that the foraging success rate of hooded cranes was not significantly correlated with food density and the relative flock size in the mixed-species foraging flock in meadows, but a significant negative correlation with the relative flock size in mudflats. However in paddy fields it was a significant positive correlation with the relative flock size. Foraging efforts of hooded cranes were negatively correlated with food density and positively correlated with the relative flock size in meadows. In mudflats, foraging efforts of hooded cranes had a significant positively correlation with the relative flock size, however, there was a significant negative correlation with the relative flock size in paddy fields. To sum up, larger numbers of geese mixed with hooded cranes has a favorable effect on the foraging of hooded cranes in meadows and mudflats, however, the reverse was observed in the paddy fields.
\end{abstract}

Keywords: mixed-species foraging; hooded crane; wild geese; wintering waterbird; interspecific interaction; Shengjin Lake

\section{Introduction}

Mixed-species foraging of waterbirds is a relatively common phenomenon [1]. When large flocks of multiple species of waterbirds are foraging in small habitats, each species is inevitably affected by the other [2]. The waterbirds then adopt flexible foraging strategies to ensure they find enough food [3]. When waterbird species with similar dietary requirements forage in the same habitat with limited foraging resources, the foraging success rate of the various groups should be lower than that in the presence of a single species due to overlapping ecological niches and inter-specific competition [4]. Therefore, to obtain sufficient food, the foraging efforts of the various groups of water birds should 
be increased $[5,6]$. When waterbird species with varying nutritional requirements exist in the same habitat, the foraging of one species may favorably affect the other waterbird groups as a result of reduced competition for foraging resources. This is reflected in the feeding activities of three species of storks: the black-necked stork (Ephippiorhynchus asiaticus), painted stork (Mycteria leucocephalus) and Asian open-bill storks (Anatosmus oscitans) in the Keoladeo National Park of India. When one species of the stork feeds on fish at a different water depth, the population density of fish increases due to decreased predator competition, which improves the feeding of the other stork species, and the foraging success rate increases and foraging efforts decrease [7].

The wintering period is an important stage in the life of migratory waterbirds. During this period, wintering waterbirds need to forage to obtain energy to replenish the large amounts consumed during the long migration, and also need to store energy for the return to their breeding grounds at the end of winter $[8,9]$. In wintering grounds with low food quality, foraging not only affects the waterbirds' survival through winter and their physiological energy and nutritional needs, but is also significant for their continued migration and the successful maintenance of their life cycle. As the basis of all other behaviors during the wintering period, foraging is therefore the most important characteristic of migratory waterbirds $[7,10]$.

The hooded crane (Grus monacha) is a National Class I key protected wild bird species in China with a population size of approximately 11,000 worldwide. It is on the International Union for Conservation of Nature (IUCN) Red List of Threatened Species [11]. This crane breeds in Siberia, Russia, and Northeast China. Approximately 300 of these cranes annually migrate to Shengjin Lake, Anhui, China, for the wintering season [12]. At the same time, a large number of geese, mainly greater white-fronted geese (Anser albifrons), lesser white-fronted geese (Anser erythropus), and bean geese (Anser fabalis), also migrate south arriving at Shengjin Lake every October, with a total number of exceeding 20,000 [13,14]. Throughout winter, hooded cranes huddle with the large numbers of geese to feed in the narrow and suitable habitats available around Shengjin Lake, which include meadows and mudflats, exposed after the water level drops, and also in nearby paddy fields.

During early winter, the food resources of hooded cranes at Shengin Lake are mainly submerged plants such as eel grass (Vallisneria natans) in the meadows. As the water level of the lake continues to drop, a large number of wintering waterbirds gnaw at these plants during the early stages of winter and, the submerged plant food resources reduce. Hooded cranes also feed on rice grains remaining in paddy fields, and buttercup (Ranunculus polii) in the meadows and mudflats in the middle and later stages of overwintering [13-15]. Among the geese foraging together with hooded cranes, bean geese often forage in paddy fields, mainly feeding on rice grains. Lesser white-fronted geese and greater white-fronted geese are commonly found in meadows and mudflats and their main food source is the upper part and tuber stems of eel grass, leaves and other parts of sedge (Carex unisexualis) [16-19].

It can be seen that there is no competition for food between hooded cranes, greater white-fronted geese and lesser-fronted geese in meadows and mudflats. Owing to the greater and lesser white-fronted geese feeding on the upper parts of the plants, the hooded cranes are then able to access and eat grass shoots and tubers of the plant. Hence the food needed by the hooded cranes is exposed by the feeding of these two geese species [13], which may facilitate the feeding of the hooded crane to a certain extent. In paddy fields, however, because both hooded cranes and bean geese feed on scattered rice grains, there is an overlap in the nutritional niche [20]. Here, interspecific competition may hinder the feeding of hooded cranes.

We analyzed the foraging behavior of hooded cranes at Shengjin Lake and then assessed the relationship between the flock size of geese and food density in certain foraging patches. We further explored the effect of the flock size of geese on the wintering hooded crane's foraging in different habitats. This is very significant for the management and protection of hooded cranes in the wintering habitats at Shengjin Lake. In this paper, we focused on two hypotheses: (a) in meadows and mudflats of Shengjin Lake, flocks of geese have a favorable effect on the hooded crane's foraging, and the larger the flock size of foraging geese, the lower the foraging efforts and higher foraging success rate for the 
hooded cranes; (b) in the paddy fields at Shengjin Lake, geese flocks have a negative effect on the foraging of hooded cranes, and the larger the flock size of the geese, the higher foraging effort and the higher the foraging success rate for the hooded cranes.

\section{Materials and Methods}

\subsection{Study Area}

The study sites were located in the upper part at Shengjin Lake, a shallow lake connected to the Yangtze River on the East Asian-Australasian flyway for birds. The region has a humid subtropical monsoon climate, an average annual temperature of $16.1^{\circ} \mathrm{C}$, and an annual precipitation of $1600 \mathrm{~mm}$. The dry and rainy seasons are clearly separated. The dry season lasts from November to March and in the following year, the water level fluctuates between $8 \mathrm{~m}$ to $11 \mathrm{~m}$ [21]. When the dry season starts in autumn, as a result of lake recession, wetland plants such as eel grass, sedge, and buttercups are exposed in the lake riparian and shallow zones of the upper lake. This attract a large number of geese and hooded cranes to these areas in the winter season [22]. Post-December, due to the insufficient supply of food resources for the excessive number of waterbirds, some hooded cranes and bean geese colonies leave the meadows and mudflats for the surrounding paddy fields in search of food.

This area was selected as the research site for this study due to the availability of fewer suitable habitats rich in food around Shengin Lake. Furthermore, the distribution of foraging grounds of the hooded cranes and geese groups in upper lake is relatively fixed and concentrated [12]. The data were collected using five survey sites in the meadows, mudflats, and paddy field habitats where the hooded crane and the three species of geese lived after the fall of the water level at Shengjin Lake (Figure 1).

\subsection{Division of Wintering Period and Habitat Investigation}

From mid-November 2018 to the end of March 2019, field surveys were conducted daily between 7:00 to 17:00. For the convenience of the study, the overwintering period was divided into 10 stages according to the actual situation, as follows: A (10 November to 24 November), B (25 November to 10 December), C (11 December to 25 December), D (26 December to 10 January the following year), E (11 January to 22 January), F (23 January to 12 February), G (13 February to 25 February), H (26 February to 9 March), I (10 March to 22 March), and J (23 March to 31 March). Based on available literature and field surveys, combined with the selection of feeding habitats of the hooded cranes throughout winter, the habitat types of the wintering hooded cranes at Shengjin Lake were divided into 3 types: meadows, mudflats, and paddy fields [13]. Meadows and mudflats are the main habitat for hooded cranes based on the accessibility of food. They serve as important foraging habitats for hooded cranes and, provide a sheltered place. Paddy fields are artificial foraging habitats for hooded cranes [13]. The wintering geese also gather in all three foraging habitats. 


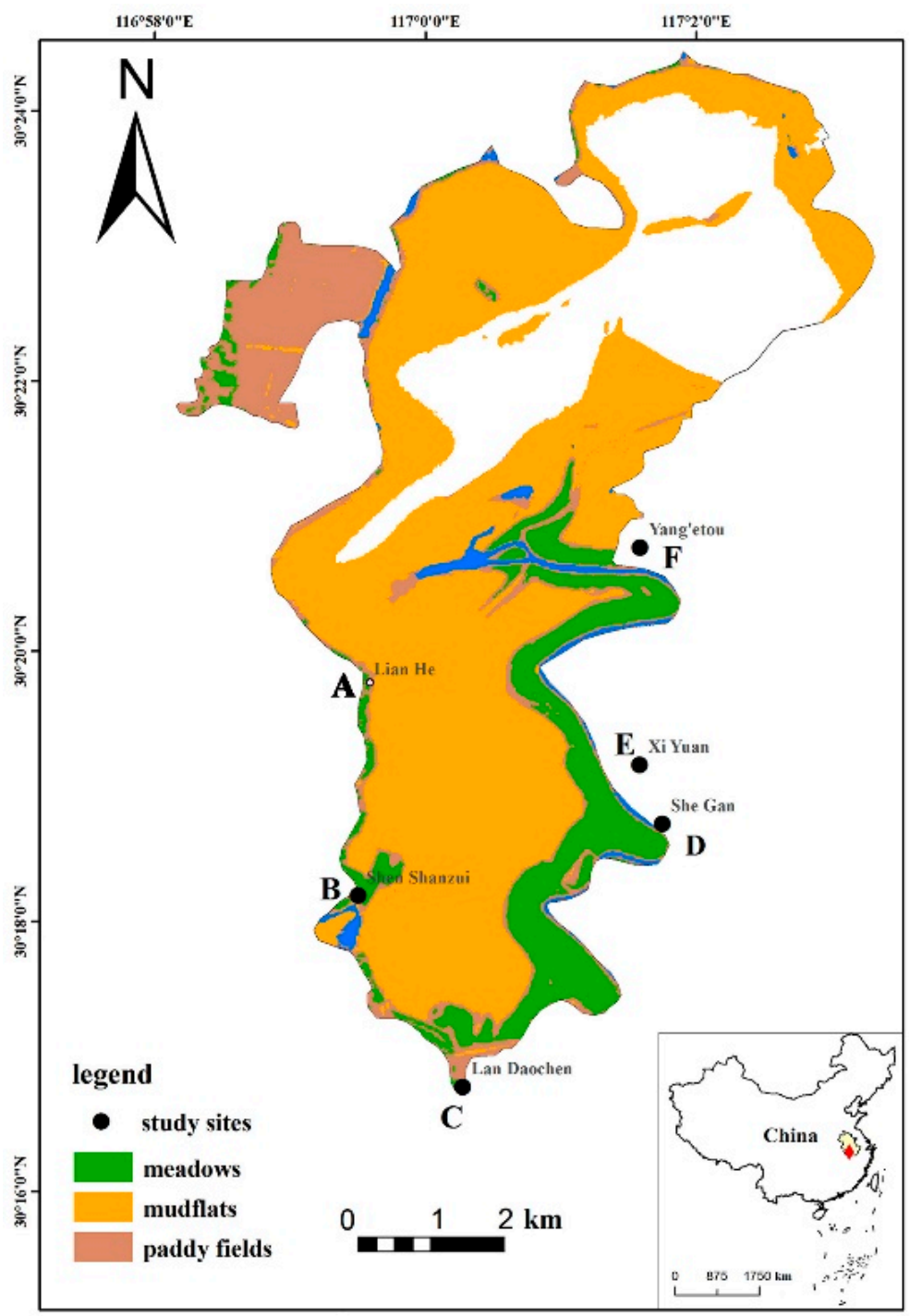

Figure 1. Foraging habitats for hooded cranes in the upper part of Shengjin Lake (A, B, C, D and E indicate the study sites).

\subsection{Interspecific Survey and Behavioral Observations}

During the study period, a direct counting method was applied every day to survey the number of hooded cranes and geese. The survey began at 7:00. Once a group of geese was located, the entire visible sites were scanned clockwise using a telescope (ATS80-20-60×, Swarovski, Absam, Austria). The number of foraging geese in each habitat was recorded. In order to reduce the effects of severe weather on the observations, the survey was postponed to the following day on days with strong winds, thick fog, or heavy snow. Behavioral observations were also carried out on all clear days between November 2018 and March 2019. Focal sampling was conducted with binoculars (EL10×32WB, Swarovski, Absam, Austria) and a telescope (ATS80-20-60×, Swarovski, Absam, Austria) was used to record behavioral patterns from 7:00 to 17:00. At the beginning of each focal observation, the date, time, location, and habitat type (paddy field, meadow, or mudflat) were recorded. The object of the observations in each group was usually a single adult. All observations were made from relatively remote locations, to avoid the presence of the investigators impacting the behavior of the waterbirds. A voice recorder (ICD-UX544F, Sony, Tokyo, Japan) was used to record vocal behavior for $20 \mathrm{~min}$, and unless sight of the focal individuals was lost, the ethogram comprised the following types of behavior: foraging, alertness, social behavior, movement, and resting [23,24]. Obvious swallowing behavior was considered as a 
sign of successful foraging. The movements of the beak and neck were observed to ascertain if a hooded crane was foraging. When the grass was over $14 \mathrm{~cm}$ high, it concealed the beak and neck of the hooded cranes, and their behavioral patterns were hence difficult to observe, these observations were abandoned. The foraging success rate was defined as the number of times a hooded crane successfully captured food in a foraging round relative to the duration of the round, and it reflected the quality of foraging of the hooded cranes. The foraging effort was defined as the total time spent on all foraging-related behaviors in a foraging round (such as snooping, capturing, processing, swallowing, and drinking), compared to the duration of the round, and reflected the quality of foraging habitats. It also reflected the distribution of daily energy requirements and behavioral patterns, showing that the hooded cranes were more flexible to responding to changes in food density. At the same time, no correlation was seen between foraging success rate and foraging effort [25]. Relative flock size was defined as the proportion of individual hooded cranes compared to the number of geese in the same foraging habitat at a given time.

\subsection{Food Resources Survey}

Sample areas (10-13) were randomly selected every 10 days on average each of the different habitats that were used for feeding by the hooded cranes between 10 November 2018 to 31 March 2019 . The size of the samples areas was $0.5 \mathrm{~m} \times 0.5 \mathrm{~m}$. In the meadows, we collected the tubers and roots of eel grass, buttercup and Chinese cinquefoil herb (Potentilla chinensis); in the mudflats we collected the tubers and roots of Chinese cinquefoil herb (Potentilla chinensis) and some molluscs such as Anodonta woodiana and Cipangopaludina cahayensis; in the paddy fields we collected the grain ear of rice. We collected all the aboveground material, and the samples were then taken to the laboratory and dried at $60{ }^{\circ} \mathrm{C}$ in an oven (YHG-9050A; Derip, Suzhou, China), for a period of $72 \mathrm{~h}$ or less, to achieve a constant weight, which represented the dry weight $(\mathrm{g})$ and recorded it to the nearest $0.01 \mathrm{~g}$. We defined the dry weight of the food items in a quadrat $\left(0.25 \mathrm{~m}^{2}\right)$ as food density $\left(\mathrm{g} / \mathrm{m}^{2}\right)$. In order to ensure the independence of the data samples, the distance between two adjacent quads was required to be $\geq 50 \mathrm{~m}[26]$.

\subsection{Data Analysis}

We defined the two independent variables as food density and the relative flock size in the same habitat, the two dependent variables were foraging success rate and foraging efforts of hooded cranes.

Microsoft Excel 2013 (Microsoft, Redmond, WA, USA) was used to calculate the average and standard error of food density, the relative flock size, and hooded cranes' foraging success rate and foraging effort at each stage, and we made bar charts with SigmaPlot14.0 (Systat Software, San Jose, CA, USA).

Prior to analysis, we tested multicollinearity between two independent variables using Pearson correlations, and all variables were retained because all correlation coefficients were below 0.6 , and the Kruskal-Wallis $H$ test was used to determine the differences in each variable in the three habitats. We used the Kolmogorov-Smirnov test to find that all the data did not fully conform to the normal distribution, hence the foraging success rate, foraging effort, and the related flock size data were changed by an inverse tangent transformation as $\arctan (X)$, to conform to the statistical requirements; the food density was changed by a logarithmic transformation as $\operatorname{Ln}(X+1)$, to conform to the statistical requirements. All analyses were performed based on the data obtained after the conversion.

Pearson correlations were then used to test correlation between each independent variable and the dependent variable. Finally, a linear regression model was used to analyze the linear relationship between each independent variable and dependent variable.

Statistical analysis was performed on all collected data using Microsoft Excel 2013 (Microsoft, Redmond, WA, USA), IBM SPSS22.0 (IBM, Armonk, NY, USA), and SigmaPlot14.0 (Systat Software, San Jose, CA, USA) statistical software. A significance level of $0.05(p)$ was used for all statistical tests, with means expressed as mean \pm standard error (SE). 


\section{Results}

\subsection{Dynamic Changes in Food Density and Relative Population Size}

There were significant differences in the dynamic changes to food density in the three types of habitats in the upper lake of Shengjin Lake $\left(p<0.05, \chi^{2}=298.922, \mathrm{df}=2\right)$. The food density in the meadows decreased between period $\mathrm{A}$ and $\mathrm{F}$, and then started to increase during period $\mathrm{G}$. The change in food density in the mudflats was consistent with the trend in the meadows. The food density in the paddy fields decreased gradually from period A to I (Figure 2a).
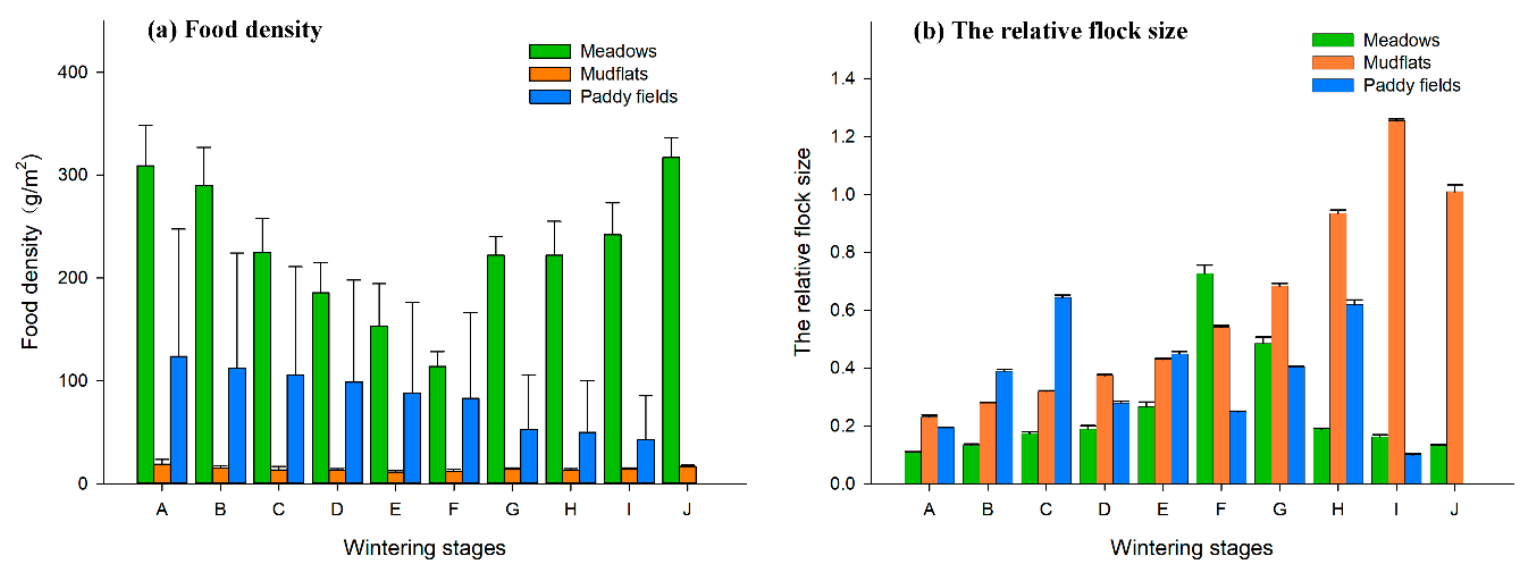

Figure 2. Dynamic changes of food density (a) and ratio of the number of hooded cranes to the number of geese (b) during wintering at Shengjin Lake (A-J stand for wintering stages, and their meaning is shown in Section 2.2).

There were significant differences in the dynamic changes to the relative flock size of hooded cranes and geese in the three types of habitats in the upper lake area of Shengjin Lake $(p<0.05$, $\chi^{2}=118.098, \mathrm{df}=2$ ). The relative flock size in the meadows increased from period $\mathrm{A}$ to $\mathrm{F}$, and then decreased; the relative flock size in the mudflats increased from period A to I, and then decreased in period J; the relative flock size in the paddy fields gradually increased from period A to $C$, and then constantly fluctuated (Figure $2 b$ ).

\subsection{Dynamic Changes of Foraging Success and Foraging Efforts of Hooded Cranes}

There were significant differences in the foraging efforts of hooded crane flock in the three types of habitats in the upper lake area of Shengjin Lake $\left(p<0.05, \chi^{2}=10.521, \mathrm{df}=2\right)$. In winter, foraging efforts of hooded cranes flock in the meadows increased from period A to F, and then gradually decreased. The foraging efforts in the mudflats showed an increasing trend from period $\mathrm{A}$ to $\mathrm{F}$, and fluctuated thereafter. The foraging efforts of hooded cranes in the paddy fields decreased from period A to C, and showed a further slow decline from period $\mathrm{D}$ to $\mathrm{H}$. Throughout the last wintering period I, the hooded cranes were primarily in the paddy fields and a large number bean geese moved to the meadows during this period, so the interspecies relationship had little effect on foraging efforts. Lower food density is the reason for high foraging efforts during period I (Figure 3a).

There were significant differences in the foraging success rate of hooded crane flock in the three types of habitats in the upper lake area of Shengjin Lake $\left(p<0.05, \chi^{2}=72.287, \mathrm{df}=2\right)$. The foraging success rate of hooded cranes in the meadows decreased from period $A$ to $F$, and then gradually increased; the foraging success rate of hooded cranes in mudflats decreased from period A to E, and thereafter gradually increased; in the paddy fields the foraging success rate of hooded cranes increased from period A to C, after which it began to greatly fluctuate from period D onwards (Figure 3b). 

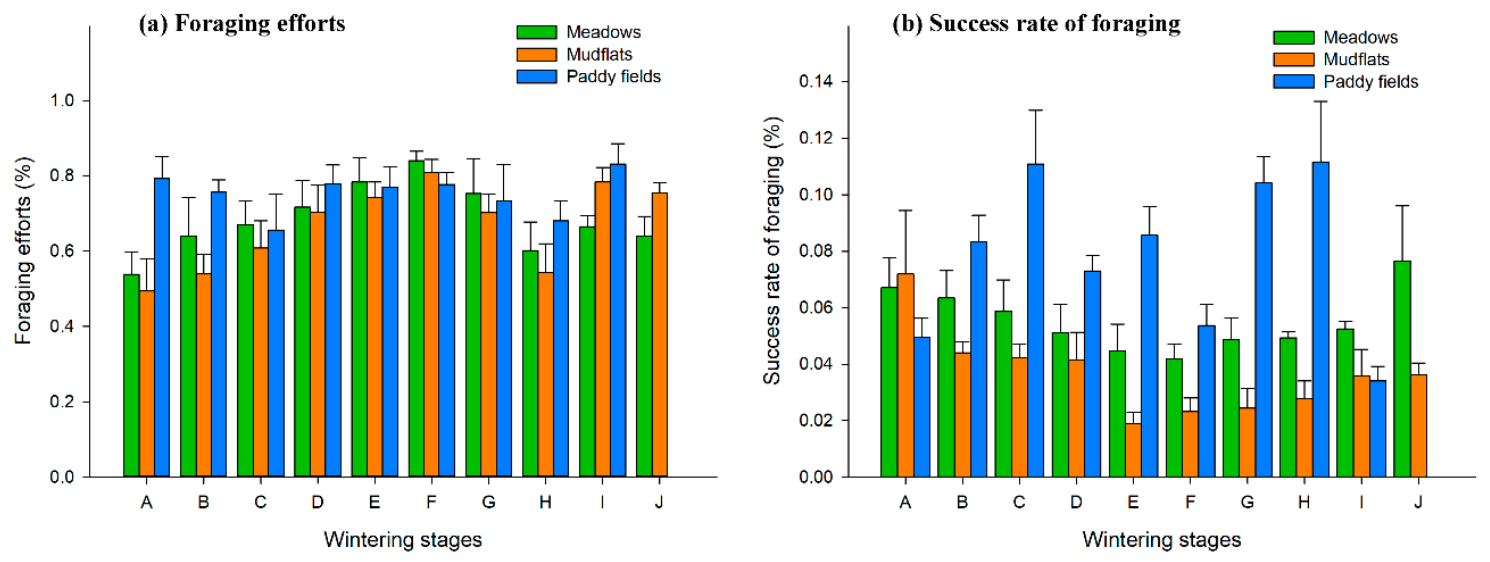

Figure 3. Dynamic changes of foraging efforts (a) and success rate of foraging (b) during wintering at Shengjin Lake (A-J stand for wintering stages, and their meaning is shown in Section 2.2).

3.3. Correlation between the Success Rate of Foraging Cranes and Food Density, and the Proportion of the Number of Cranes and Geese

In the meadows, correlation analysis showed that there was no significant correlation between foraging success rate and food density $(r=0.134, p>0.05, n=134)$, and between foraging success and the relative flock size $(r=-0.151, p>0.05, n=134)$ (Table 1$)$.

Table 1. The correlation between the foraging success rate of hooded crane and the influencing factors at Shengjin Lake.

\begin{tabular}{|c|c|c|c|c|}
\hline Dependent Variable & Habitat & Analysis Value & Food Density $\left(\mathrm{g} / \mathrm{m}^{2}\right)$ & Relative Flock Size \\
\hline \multirow{9}{*}{ Foraging success } & \multirow{4}{*}{ Meadows } & $r$ & 0.134 & -0.151 \\
\hline & & $p$ & 0.121 & 0.082 \\
\hline & & $n$ & 134 & 134 \\
\hline & & $r$ & 0.133 & -0.176 \\
\hline & \multirow{2}{*}{ Mudflats } & $p$ & 0.127 & 0.043 \\
\hline & & $n$ & 132 & 132 \\
\hline & \multirow{3}{*}{ Paddy fields } & $r$ & 0.067 & 0.525 \\
\hline & & $p$ & 0.491 & 0.000 \\
\hline & & $n$ & 109 & 109 \\
\hline
\end{tabular}

In the mudflats, correlation analysis showed that there was no significant correlation between the foraging success rate and food density of the hooded crane $(r=0.133, p>0.05, n=132)$; but a significant negative correlation was noted with the relative flock size $(r=-0.176, p<0.05, n=132)$ (Table 1).

In the paddy fields, correlation analysis showed that there was no significant correlation between foraging success rate and food density $(r=0.067, p>0.05, n=109)$; but a substantial significant positive correlation was noted with the relative flock size $(r=0.525, p<0.05, n=109)$ (Table 1).

\subsection{Correlation between Foraging Efforts of the Hooded Crane and Food Density, and the Proportion of Hooded Cranes to Geese}

In the meadows, correlation analysis showed that there was a significant negative correlation between foraging efforts and food density ( $r=-0.221, p<0.05, n=134)$, and a significant positive correlation was observed between foraging efforts and the relative flock size $(r=0.258, p<0.05, n=134)$ (Table 2).

In the mudflats, no significant correlation was observed between foraging efforts and food density ( $r=-0.076, p>0.05, n=132)$; but a significant positive correlation was seen between foraging efforts and the relative flock size $(r=0.238, p<0.05, n=132)$ (Table 2$)$. 
In the paddy fields, there was no significant correlation between foraging efforts and food density $(r=-0.039, p>0.05, n=109)$. A significant negative correlation was seen between foraging efforts and relative population size $(r=-0.237, p<0.05, n=109)$ (Table 2$)$.

Table 2. The correlation between the foraging effort of hooded crane and the influencing factors at Shengjin Lake.

\begin{tabular}{ccccc}
\hline Dependent Variable & Habitat & Analysis Value & Food Density $\left(\mathrm{g} / \mathbf{m}^{\mathbf{2}}\right)$ & Relative Flock Size \\
\hline \multirow{6}{*}{ Meadows } & $r$ & -0.221 & 0.258 \\
& & $p$ & 0.010 & 0.003 \\
& & $n$ & 134 & 134 \\
& & $r$ & -0.076 & 0.238 \\
& \multirow{3}{*}{ Mudflats } & $p$ & 0.389 & 0.006 \\
& & $n$ & 132 & 132 \\
& \multirow{4}{*}{ Paddy fields } & $r$ & -0.039 & -0.237 \\
& & $p$ & 0.690 & 0.013 \\
& & $n$ & 109 & 109 \\
\hline
\end{tabular}

To summarize, the linear regression equation models of the hooded crane's foraging success rate, foraging effort and food density, and relative flock size are as follows:

Foraging effort $=-0.049 \times$ food density $+0.251 \times$ relative flock size $+0.781\left(R^{2}=0.087, F_{2,131}=6.211\right.$, $p=0.003)$ in meadow habitats.

Foraging effort $=0.183 \times$ relative flock size $+0.480\left(R^{2}=0.057, F_{1,130}=7.820, p=0.006\right)$ in mudflat habitats.

Foraging success rate $=-0.027 \times$ relative flock size $+0.050\left(R^{2}=0.031, F_{1,130}=4.177, p=0.043\right)$ in mudflat habitats.

Foraging effort $=-0.244 \times$ relative flock size $+0.716\left(R^{2}=0.056, F_{1,107}=6.356, p=0.013\right)$ in paddy field habitats.

Foraging success rate $=0.165 \times$ relative flock size $+0.021\left(R^{2}=0.276, F_{1,107}=40.699, p=0.000\right)$ in paddy field habitats.

\section{Discussion}

According to the optimal foraging theory, animals seek to maximize their own benefits [27]. Foraging is a high-energy-consumption behavior. Under ideal conditions, mammals and birds seek food with a high net energy and spend as little time as possible in search of food, to reduce energy expenditure. That is to say, foraging efforts need to be as low as possible. Therefore, lower foraging efforts and higher foraging success rates are indicators of efficient foraging [28,29].

Over the wintering period, hooded cranes inhabit meadows, mudflats, and paddy fields on the upper lake of Shengjin Lake. They cohabitate with three species of geese (bean geese, greater white-fronted geese and lesser white-fronted geese). Under the availability of different food densities and dependent on the size of the geese flocks in the various habitats, the foraging behavior of the hooded cranes differs.

In meadows, the foraging success rate of the hooded crane was not significantly correlated to food density and relative flock size; however, the foraging efforts were significantly negatively correlated to food density, and positively correlated to the relative flock size. This shows that in meadows, the greater the relative density of food and the larger the flock of geese, the less time it takes for the hooded crane to forage. This result validates the hypothesis that the presence of large numbers of geese in the meadow habitats facilitates the foraging of hooded cranes. This phenomenon occurred is because waterbirds have effective way of avoiding over-competition during winter: based on food niche separation [30]. The geese consume the upper part of the sedge and eel grass [31,32], exposing the main food source of hooded cranes in the meadows- the tuber parts of the eel grass and buttercups-increasing their availability. The hooded crane hence spends less time foraging based on meeting their food requirement [33]. In addition, there is interspecific competition between sedge, eel 
grass, and buttercups [34,35]. When the geese eat the sedge, plants such as eel grass, and buttercups can grow better, thus increasing the hooded cranes' food supply.

The same trend is seen in mudflats, the only difference being that the food density is relatively smaller compared to that in the meadows, and hence the correlation between food density factors and the hooded cranes' foraging behavior in mudflats is not significant.

In paddy fields, the foraging success rate of hooded cranes was a significantly positively correlated with the relative flock size. A significant negative correlation was seen between the feeding efforts of hooded cranes and the relative flock size. This shows that in the paddy fields, larger geese flock sizes and lower food density reduced the foraging success rate of hooded cranes; meanwhile, smaller geese flock sizes led to lower foraging efforts. These results also validate the hypothesis that in the paddy fields, larger geese flocks make foraging more difficult for the cranes, because the only food available to both waterbird species is rice [36]. Hence, there is overlap in both the trophic and spatiotemporal niches of both species [37]. When bean geese and hooded cranes forage together in the paddy fields, the geese consume the rice and rice ears, which lead to the cranes spending more time and efforts foraging in search of food. The foraging success rate of the hooded cranes therefore decreases due to the reduced food density in the habitat.

Corresponding to plant growth characteristics, the food density in the meadows and mudflats at Shengjin Lake first decreased and then increased, from autumn and winter, to the beginning of spring the following year. After autumn, the plants no longer grow, and the foraging of large-scale wintering waterbirds further reduces the number of plants. Into spring, wintering waterbirds migrate northward and the plants are able to regrow, the food density in the paddy fields decreases up to this point, because the rice grains left behind by farmers after the autumn harvest are foraged by geese and hooded cranes, and cannot regrow in the spring [38]. These affect and may limit the types and amount of food available for hooded cranes. Due to the unique climate and geographical characteristics at Shengjin Lake, food resources may often be concentrated in certain areas within certain time periods [16,39]. Flocks of geese simultaneously cluster in the habitats such as meadows and mudflats where hooded cranes feed, further straining the availability and utilization of food resources by the hooded crane.

Thus, it can be seen that interspecific competition is not unique or dominant in the foraging of a variety of wintering waterbirds. It is often assumed that when two or more species of large waterbirds gather in the same narrow foraging habitat, they adversely affect each other, by competing for food, occupying space, or driving each other away [40]. Mutually beneficial relationships are seen among various groups that live together harmoniously.

Based on the results of this study, the reserve manager at Shengjin Lake can carry out targeted conservation work on protecting hooded cranes, by means such as increasing the supply of available food resources such as eel grass, buttercup, and Chinese cinquefoil herb through vegetation restoration in the meadows and mudflats. Meanwhile, human interference should continue to be eliminated so that hooded cranes may spend more time foraging. In habitats such as paddy fields, managers need to artificially increase the availability of rice grains to the waterbirds after the harvest. Proactive measures need to be taken on a large-scale to spread and increase the availability of foraging habitats to hooded cranes and avoid intense inter-specific competition with other waterbirds such as bean geese. These approaches will allow the endangered hooded cranes to obtain food more easily at the Shengjin Lake wetland and reduce the foraging efforts, hence being beneficial to their protection and survival. Future research needs to further explore the influence of the geese flocks on the food resources available to the hooded cranes, so as to explore the in depth interspecific relationship between hooded cranes and geese.

Author Contributions: Z.Z. and L.Z. conceived and designed the experiments. Z.Z. performed the experiments, Z.Z. and L.Z. analyzed the data. L.Z. and L.C. contributed the materials/analysis tools and Z.Z. and L.Z. wrote the paper. L.Z. liaised with reserve authorities and obtained province guidance and permission for the field work. Y.S., C.Y., L.C., and W.X. participated in the field work. All authors have read and agreed to the published version of the manuscript. 
Funding: The study was supported by the National Natural Science Foundation of China (Grant No. 31772485 and 31472020).

Acknowledgments: We thank the staff of Anhui Shengjin Lake National Nature Reserve for their help with the field work.

Conflicts of Interest: The authors declare no conflict of interest.

\section{References}

1. Ye, F.; Huang, C.M.; Li, H.H. Study on spatial niche of seven species of colonial breeding egrets and herons of Fangcheng, Guangxi Autonomous Region. Sichuan J. Zool. 2006, 3, 577-583.

2. Hino, T. Mutualistic and commensal organization of avian mixed-species foraging flocks in a forest of Western Madagascar. J. Avian Biol. 1998, 29, 17-24. [CrossRef]

3. Weimerskirch, H.; Corre, M.L.; Jaquemet, S.; Marsac, F. Foraging strategy of a tropical seabird, the red-footed booby, in a dynamic marine environment. Mar. Ecol. Prog. Ser. 2005, 288, 251-261. [CrossRef]

4. Malpica, A.; Covarrubias, S.; Villegas-Patraca, R.; Herrera-Alsina, L. Ecomorphological structure of avian communities' changes upon arrival of wintering species. Basic Appl. Ecol. 2017, 24, 60-67. [CrossRef]

5. Cope, D.R. Variation in daily and seasonal foraging routines of non-breeding barnacle geese (Branta leucopsis): Working harder does not overcome environmental constraints. J. Zool. 2010, 260, 65-71. [CrossRef]

6. Weimerskirch, H.; Gualt, A.; Cherel, Y. Prey distribution and patchiness: Factors in foraging success and efficiency of wandering albatrosses. Ecology 2005, 86, 2611-2622. [CrossRef]

7. Ishtiaq, F.; Javed, S.; Coulter, M.C.; Rahmani, A.R. Resource partitioning in three sympatric species of storks in Keoladeo National Park, India. Waterbirds 2010, 33, 41-49. [CrossRef]

8. Matuszak, A.; Mörtl, M.; Quillfeldt, P.; Bauer, H.G. Macrophyte-associated macro invertebrates as an important food source for wintering waterbirds at Lake Constance. Limnology 2014, 15, 69-76. [CrossRef]

9. Booth, J.M.; Steinfurth, A.; Fusi, M.; Cuthbert, R. Foraging plasticity of breeding northern rockhopper penguins, Eudyptes moseleyi, in response to changing energy requirements. Polar Biol. 2018, 41, 1815-1826. [CrossRef]

10. Rayner, M.J.; Hartill, B.W.; Hauber, M.E.; Phillips, R.A. Central place foraging by breeding Cook's petrel Pterodroma cookii: Foraging duration reflects range, diet and chick meal mass. Mar. Biol. 2010, 157, 2187-2194. [CrossRef]

11. Rasmussen, P.C. Threatened birds of Asia: The birdlife international red data book. Auk 2004, 121, 619-622. [CrossRef]

12. Zhao, G.H.; Zhou, L.Z.; Dong, Y.Q.; Song, Y.W. The temporal variations of gut microbiota composition in overwintering Hooded Crane (Grus monacha) at Lake Shengjin, Anhui Province. J. Lake Sci. 2017, 29, 670-677.

13. Zhao, F.T.; Zhou, L.Z.; Xu, W.B. Habitat utilization and resource partitioning of wintering hooded cranes and three goose species at Shengjin Lake. Chin. Birds 2013, 4, 281-290. [CrossRef]

14. Fox, A.D.; Cao, L.; Zhang, Y.; Brater, M.; Wang, S.L. Declines in the tuber-feeding waterbird guild at Shengjin Lake National Nature Reserve, China-A barometer of submerged macrophyte collapse: Marine and freshwater ecosystems. Aquat. Conserv. Mar. Freshwater Ecosyst. 2011, 21, 82-91. [CrossRef]

15. Xu, L.L.; Xu, W.B.; Sun, Q.Y.; Song, Y.W.; Zhou, Z.Z.; Shen, J.; Zhao, X.X. Flora and vegetation in Shengjin Lake. J. Wuhan Bot. Res. 2008, 44, 116-121. (In Chinese)

16. Fox, A.D.; Cao, L.; Barter, M. The functional use of East Dongting Lake, China, by wintering geese. Wildfowl 2008, 58, 3-19.

17. Fox, A.D.; Zhao, M.J.; Cao, L. Distribution and diet of wintering tundra bean geese (Anser fabalis) serrirostris at Shengjin Lake, Yangtze River floodplain, China. Wildfowl 2010, 60, 52-63.

18. Polakowski, M.; Kasprzykowski, Z. Differences in the use of foraging grounds by greylag goose Anser anser and white-fronted goose Anser albifrons at a spring stopover site. Avian Biol. Res. 2016, 9, 265-272. [CrossRef]

19. Karmiris, I.; Kazantzidis, S.; Platis, P.; Papachristou, T.G. Diet selection by wintering lesser white-fronted goose Anser erythropus and the role of food availability. Bird Conserv. Int. 2017, 27, 1-16. [CrossRef]

20. Kim, M.K.; Lee, S.I.; Lee, S.D. Habitat use and its implications for the conservation of the overwintering populations of bean goose Anser fabalis and greater white-fronted goose Anser albifrons in South Korea. Ornithologicalence 2016, 15, 141-149. [CrossRef] 
21. Hu, W.H.; Yu, G.Q.; Liu, Z.Y. The ecology environment and its protection of Shengjin Lake wetland. Territory Nat. Resour. Study 2004, 4, 70-71.

22. Yang, L.; Dong, B.; Wang, Q.; Sheng, S.W.; Han, W.Y.; Zhao, J.; Cheng, M.W.; Yang, S.W. Habitat suitability change of water birds in Shengjin Lake National Nature Reserve, Anhui Province. J. Lake Sci. 2015, 27, 1027-1034. [CrossRef]

23. Zhou, B.; Zhou, L.Z.; Chen, J.Y.; Cheng, Y.Q.; Xu, W.B. Diurnal time-activity budgets of wintering Hooded Cranes (Grus monacha) in Shengjin Lake, China. Waterbirds 2010, 33, 110-115. [CrossRef]

24. Masatomi, H. Individual (non-social) behavioral acts of hooded cranes Grus monacha wintering in Izumi, Japan. J. Ethol. 2004, 22, 69-83. [CrossRef]

25. Wan, W.J.; Zhou, L.Z.; Song, Y.W. Shifts inforaging behavior of wintering hooded cranes (Grus monacha) in three different habitats at Shengjin Lake, China. Avian Res. 2016, 7, 167-173. [CrossRef]

26. O'Connell, M.J.; Ward, R.M.; Onoufriou, C.; Winfield, I.J.; Harris, G.; Jones, R.; Yallop, M.L.; Brown, A.F. Integrating multi-scale data to model the relationship between food resources, waterbird distribution and human activities in freshwater systems: Preliminary findings and potential uses. Ibis 2010, 149, 65-72. [CrossRef]

27. Yahnke, C.J. Optimal foraging theory. Am. Biol. Teach. 2006, 268, 583-584.

28. Weimerskirch, H.; Cherel, Y.; Cuenot-Chaillet, F.; Ridoux, C.C. Alternative foraging strategies and resource allocation by male and female wandering albatrosses. Ecology 1997, 78, 2051-2063. [CrossRef]

29. Jiang, H.X.; Xu, W.B.; Qian, F.W.; Zhong, C.G. Impact of habitat evolvement and human disturbance on wintering water birds in Shengjin Lake of Anhui Province, China. Chin. J. Appl. Ecol. 2007, 18, 1832.

30. Wang, Y.; Hu, J.C.; Chen, L.M.; Zhang, H.F.; Hu, Z.J.; Xu, L.; Xu, H.F. Preliminary study on spatial niches of small mammals in Tangiiahe nature reserve. Acta Theriol. Sin. 2005, 25, 379-384.

31. Feng, D.D.; Guan, L.; Shi, L.L.; Zeng, Q.; Liu, X.K.; Zhang, H.; Lei, G.C. Impact of autumn hydrologic regime on plants in beach and distribution of populations of wintering Lesser white-fronted goose in East Dongting Lake. Wetl. Sci. 2014, 12, 491-498.

32. Guo, H.; Shao, M.Q.; Hu, B.H.; Pang, J.P.; Yu, G.J. Wintering behavioral features and niche partition of two species of Anser iformes birds Anser cygnoide and Anser albifrons at Nanji Wetland National Nature Reserve, Poyang Lake. J. Ecol. Rural Environ. 2016, 32, 90-95.

33. Amano, T.; Ushiyama, K.; Fujita, G.; Higuchi, H. Costs and benefits of flocking in foraging white-fronted geese Anser albifrons: Effects of resource depletion. Proc. Zool. Soci. Lond. 2006, 269, 111-115. [CrossRef]

34. Gustafsson, C.; Christoffer, B. Influence of neighboring plants on shading stress resistance and recovery of eelgrass, Zostera marina L. PLoS ONE 2013, 8, e64064. [CrossRef] [PubMed]

35. Connolly, J.; Wayne, P.; Bazzaz, F.A. Interspecific competition in plants: How well do current methods answer fundamental questions? Am. Nat. 2001, 157, 107-125. [CrossRef] [PubMed]

36. Guo, J.L.; Liu, X.H.; Yang, P.; Xu, B. Spring migration route and stopovers of bean goose (Anser fabalis) in China. Chin. J. Zool. 2015, 50, 288-293. (In Chinese)

37. Zhang, P.Y.; Zou, Y.A.; Xie, Y.H.; Zhang, H.; Liu, X.K.; Gao, D.L.; Yi, F.Y. Shifts in distribution of herbivorous geese relative to hydrological variation in East Dongting Lake wetland, China. Sci. Total Environ. 2018, 636, 30-38. [CrossRef]

38. Zhang, X.K.; Liu, X.Q.; Wang, H.Z. Effects of water level fluctuations on lakeshore vegetation of three subtropical floodplain lakes, China. Hydrobiologia 2015, 747, 43-52. [CrossRef]

39. Liu, J.L.; Zhou, Z.Z.; Tian, H.X.; Wan, Y.; Zhao, L.N. Vascular plant community types and flora in Shengjin Lake National Nature Reserve. J. Biol. 2016, 33, 40-46.

40. Gaston, K.J.; Blackburn, T.M.; Gregory, R.D. Interspecific abundance-range size relationships: Range position and phylogeny. Ecography 2010, 20, 390-399. [CrossRef]

(C) 2020 by the authors. Licensee MDPI, Basel, Switzerland. This article is an open access article distributed under the terms and conditions of the Creative Commons Attribution (CC BY) license (http://creativecommons.org/licenses/by/4.0/). 